\title{
Regulation of Cytochrome Oxidase Protein Levels by Functional Activity in the Macaque Monkey Visual System
}

\author{
Robert F. Hevner and Margaret T. T. Wong-Riley \\ Department of Anatomy and Cellular Biology, Medical College of Wisconsin, Milwaukee, Wisconsin 53226
}

The activity of cytochrome oxidase (CO), a mitochondrial enzyme of oxidative energy metabolism, is regulated by nerve cell functional activity. The mechanism of $\mathrm{CO}$ activity regulation was studied using histochemical and immunohistochemical methods to show the distributions of $\mathrm{CO}$ activity and protein, respectively, in the macaque monkey visual system under normal and experimental conditions. In normal animals, patterns of $\mathrm{CO}$ activity were found to reflect underlying patterns of $\mathrm{CO}$ protein distribution; for example, puffs of high $\mathrm{CO}$ activity in cortical area 17 contained high levels of $\mathrm{CO}$ protein. Experimental animals were injected monocularly with TTX for 3-4 weeks; this treatment blocks retinal impulses in the injected eye and results in decreased CO activity in lateral geniculate laminae and striate cortical columns normally driven by the treated eye. The experimentally induced decreases in CO activity were also found to reflect underlying parallel decreases in $\mathrm{CO}$ protein levels. These results suggest that $\mathrm{CO}$ activity is regulated mainly at the level of the local amount rather than the turnover number of the enzyme and imply that the rates of CO synthesis and/or degradation are regulated by neural functional activity.

While much progress has been made in studies of brain energy metabolism, relatively little is known about the biochemical regulation of neural energy metabolic capacity. It is known that the activities of several energy-metabolic enzymes are coupled to the functional activity of nerve cells (Dietrich et al., 1981, 1982; Wong-Riley, 1989), but it is not known how neural functional activity signals changes in enzyme activity, or at what levels (transcriptional, translational, distributional, etc.) expression of enzyme activity is regulated. These questions are important if we are to understand how nerve cell activity and nerve cell energy metabolism are linked, and how defective energy metabolic regulation causes neurological and muscular disease (Morgan-Hughes, 1986). These questions are difficult to address in brain tissue by traditional biochemical methods, since the distribution of energy metabolic enzymes is nonhomogeneous at very local (even subcellular) levels in the brain (Dietrich et al., 1981, 1982; Wong-Riley, 1989).

\footnotetext{
Received Aug. 21, 1989; revised Oct. 23, 1989; accepted Oct. 25, 1989.

This work was supported by NIH grants NS18122 and EY05439 to M.W.-R. R.F.II. is a Fellow in the Medical Scientist Training Program at the Medical College of Wisconsin. We thank Dr. V. M. Haughton and Dr. C. Nguyen-minh for generously providing monkey brain tissue; Dr. A. Haas for critically reading the manuscript; and W. Kaboord and S. Liu for assistance in the laboratory.

Correspondence should be addressed to Dr. Margaret T. T. Wong-Riley, Department of Anatomy and Cellular Biology, Medical College of Wisconsin, 8701 Watertown Plank Rd., Milwaukee, WI 53226.

Copyright (C) 1990 Society for Neuroscience $0270-6474 / 90 / 041331-10 \$ 02.00 / 0$
}

We have begun investigating these questions using a mitochondrial respiratory complex, cytochrome oxidase (CO; ferrocytochrome $c$ : oxygen oxidoreductase, EC 1.9.3.1; for review, see Kadenbach et al., 1987), as a representative energy metabolic enzyme. While $\mathrm{CO}$ is well known among neuroscientists as a marker for neural functional activity (Wong-Riley, 1989), it also serves as an excellent model for studying regulation of enzyme activity. $\mathrm{CO}$ is a key enzyme of the oxidative pathway, the major pathway of brain energy metabolism (Erecinska and Silver, 1989); the activity of $\mathrm{CO}$ is regulated by neural functional activity (Wong-Riley, 1989); histochemical (Wong-Riley, 1979) and immunohistochemical (Hevner and Wong-Riley, 1989a) methods have been developed for studying $\mathrm{CO}$ in brain tissue; and genomic and cDNA clones encoding most mammalian CO subunits have been obtained and sequenced (Anderson et al., 1981, 1982; Bibb et al., 1981; Lomax et al., 1984; Parimoo et al., 1984; Bachman et al., 1987; Suske et al., 1987; Zeviani et al., 1987, 1988; Rizzuto et al., 1988, 1989; Schlerf et al., 1988; Goto et al., 1989; Taanman et al., 1989). Thus, the role of the enzyme is well known, regulation of its activity has been demonstrated, and tools are available for studying its regulation.

We recently found (Hevner and Wong-Riley, 1989a) that local differences in CO activity (shown histochemically) seen in the normal mouse and monkey brain reflect similar local differences in CO protein concentration (shown immunohistochemically), indicating that the local activity of $\mathrm{CO}$ is normally determined mainly by enzyme protein levels, and not by modulation of the molecular activity of homogeneously distributed enzyme (see Fig. 1). This finding suggested that changes in $\mathrm{CO}$ activity induced by altered neural functional activity might likewise reflect changes in $\mathrm{CO}$ protein, i.e., that $\mathrm{CO}$ activity is regulated at the level of enzyme amount.

To test this hypothesis, we injected macaque monkeys monocularly with TTX for 3-4 weeks and examined their visual system by both $\mathrm{CO}$ histochemistry and $\mathrm{CO}$ immunohistochemistry. Treatment with TTX blocks retinal impulse activity and causes $\mathrm{CO}$ activity to decline in laminae of the lateral geniculate nucleus (LGN) and columns of the primary visual (striate) cortex specific to the treated eye (Wong-Riley and Carroll, 1984). We found that $\mathrm{CO}$ protein levels were decreased in the same regions showing reduced $\mathrm{CO}$ activity. We also examined normal animals and found that $\mathrm{CO}$ activity and amount were well correlated in the normal visual system. These results have been presented previously in abstract form (Hevner and Wong-Riley, 1988, 1989b).

\section{Materials and Methods}

Animal tissue preparation. Seven normal (Macaca fascicularis) and 3 TTX-treated ( $2 M$. radiata, $1 M$. fascicularis) adult male and female 


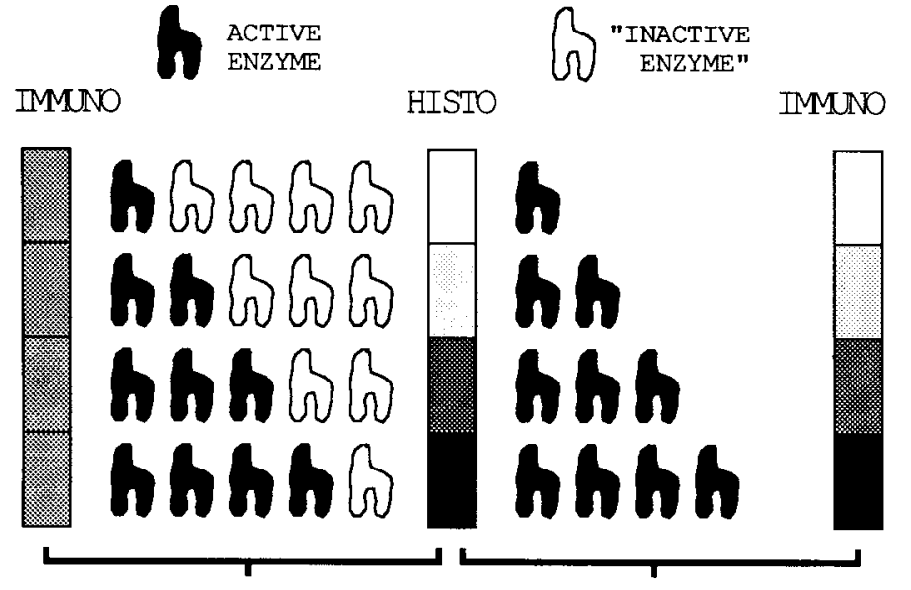

TURNOVER NUMBER-REGULATED MODEL

AMOUNT-REGULATED MODEL

Figure 1. Hypothetical models for cytochrome oxidase activity regulation. Two possible mechanisms of $\mathrm{CO}$ activity regulation, and implications of each mechanism for results of experiments, are diagrammed. Different degrees of histochemical staining intensity (CO activity) are shown in the center; at the far right and left are shown the corresponding degrees of immunohistochemical staining intensity (CO amount) expected according to each model. The models can be used to explain local $\mathrm{CO}$ activity differences in normal tissue, or changes in $\mathrm{CO}$ activity induced by altered neural functional activity (such as following TTX treatment). Our results support the amount-regulated model for both cases. (The inactive form of $\mathrm{CO}$ is at present purely hypothetical; also, regulation of the turnover number of the enzyme could simply involve modulation between more and less active forms.)

monkeys were used in this study. The normal brains came from animals used in an unrelated study and were generously provided to us by Drs. V. M. Haughton and C. Nguyen-minh. The treated animals received intravitreal TTX (Sigma; $19 \mu \mathrm{g}$ in $10 \mu \mathrm{l}$ sterile water) injections in the left eye twice a week for 3 or 4 weeks, under acepromazine $(0.8 \mathrm{mg} / \mathrm{kg})$ and ketamine $(40 \mathrm{mg} / \mathrm{kg}$ ) anesthesia, as described previously (WongRiley and Carroll, 1984). Effectiveness of the TTX was confirmed by absence of the pupillary light reflex. For euthanasia, animals were deeply anesthetized (Na pentobarbital, $65 \mathrm{mg} / \mathrm{kg}$ i.p.) and exsanguinated. The eyes and brains were removed immediately and immersed in ice-cold $4 \%$ paraformaldehyde in buffer (4\% sucrose, $0.1 \mathrm{M} \mathrm{NaP}, \mathrm{pH} 7.4)$ with agitation. Prior to immersion in fixative, the anterior portion and the vitreous body were removed from the eye, and blocks of tissue were dissected from the brain. After 4-6 hr, the tissues were rinsed in the same buffer without paraformaldehyde and then cryoprotected with cold buffer containing increasing concentrations $(10 \%, 20 \%, 30 \%)$ of sucrose. The tissue was equilibrated with each sucrose solution until it sank. Blocks of fixed tissue were frozen, sectioned at $14 \mu \mathrm{m}$ (retina) or 20-30 $\mu \mathrm{m}$ (LGN and cortex) on a freezing microtome, and placed in PBS (140 $\left.\mathrm{mM} \mathrm{NaCl}, 2.7 \mathrm{mM} \mathrm{KCl}, 1.5 \mathrm{mM} \mathrm{KP}_{\mathrm{i}}, 8.1 \mathrm{mM} \mathrm{Na}_{2} \mathrm{P}_{\mathrm{i}}, \mathrm{pH} 7.4\right)$ on ice until further processed. All samples of striate cortex came from the opercular surface. Blocks of cortex cut in the plane tangential to the surface were flattened prior to freezing and sectioning. One animal was perfusion-fixed ( $4 \%$ paraformaldehyde), but the immunohistochemical signal was lower, and the background higher, relative to immersionfixed tissue. More recently, we have obtained good results using perfusion fixation ( $4 \%$ paraformaldehyde, $0.1 \%$ glutaraldehyde) in experiments with cat thalamus (Luo et al., 1989). Our observations suggest that the degree of tissue fixation affects the structure of the antigen and/ or the penetration of antibodies into the mitochondria, and that perfused tissue may be used if fixation is mild. It is possible that the thalamus is not as strongly fixed as the cortex during perfusion, since our results in the perfused monkey were better in the LGN than in the cortex.

Histochemistry and immunohistochemistry. Alternate sections from each tissue block were processed for CO histochemistry (Wong-Riley, 1979) and CO immunohistochemistry (Hevner and Wong-Riley, 1989a); some sections were Nissl stained (1\% cresyl violet). As shown in our previous paper (Hevner and Wong-Riley, 1989a), the anti-CO antibodies have the following properties: the antibodies cross-react with $\mathrm{CO}$ from many mammalian species, including monkey and calf (calf brain CO was the immunogen); the antibodies react strongly in SDS immunoblots with subunit IV of the enzyme (and also weakly with subunits I and II), but do not react with brain proteins other than $\mathrm{CO}$; and the antibodies specifically label $\mathrm{CO}$ in immunohistochemistry, as demonstrated in both mouse and monkey brain by preimmune and preabsorbed (with purified $\mathrm{CO}$ ) controls. Free-floating sections were processed for $\mathrm{CO}$ immunohistochemistry exactly as described previously (Hevner and Wong-Riley, 1989a). Briefly, nonspecific binding was blocked with $5 \%$ nonfat dry milk (Carnation) in PBS (PBS-NFDM) containing 1-5\% normal goat serum (NGS), incubated in anti-CO (IgG preparation from rabbit antiserum) at 1:1000-8000 in PBS-NFDM with 5\% NGS, rinsed with PBS, then further incubated in PBS-NFDM-5\% NGS with either (1) HRP-conjugated goat anti-rabbit IgG (Bio-Rad blotting grade, 1:100) followed by reaction with diaminobenzidine (indirect immunoperoxidase method), or (2) fluorescein-conjugated goat anti-rabbit IgG (Boehringer Mannheim, 1:100), followed by fluorescein-conjugated swine antigoat IgG (Boehringer Mannheim, 1:100) (indirect immunofluorescence method). Fluorescence was photographed on a Nikon Optiphot equipped with epifluorescence optics and appropriate filters for fluorescein. Sections stained histochemically or by the indirect immunoperoxidase method were illuminated with blue light (Kodak Wratten No. 47 gelatin filter) for black and white photography.

Optical densitometry. Densitometric measurements were made on a Zeiss microscope fitted with a Zeiss PI-2 photometer and illuminated with a tungsten lamp. All sections used for densitometry were cut in the plane tangential to the cortical surface. Circular apertures were used to screen puff and interpuff regions of normal cortex (30- $\mu \mathrm{m}$-thick sections, 70- $\mu \mathrm{m}$-diameter regions) and dark and light (staining intensity) ocular dominance columns in cortex from TTX-treated animals (20$\mu \mathrm{m}$-thick sections, $150-\mu \mathrm{m}$-diameter regions). In each section, 25 regions of each type were sampled. Only adjacent histochemically and immunohistochemically stained sections were used for analysis. Means and standard deviations were normalized to yield a relative optical density of 1.00 in interpuffs (in normal cortex) or in dark ocular dominance columns (in experimental cortex) for each section.

\section{Results}

The retina, LGN, and striate cortex of 7 normal and 3 TTXtreated macaques were examined by $\mathrm{CO}$ histochemistry and $\mathrm{CO}$ immunohistochemistry. At the dosage given, TTX does not block axoplasmic transport (Wong-Riley and Riley, 1983; Riccio and Matthews, 1985), nor does TTX (0.2 mM) inhibit the activity of $\mathrm{CO}$ in vitro (results not shown).

Results were similar among animals within the normal group and within the TTX-treated group; results from both groups are presented together by region to clearly show the effects of TTX treatment. The patterns of $\mathrm{CO}$ histochemical staining have been described previously for both normal (Horton and Hubel, 1981; Horton, 1984; Kageyama and Wong-Riley, 1984) and TTXtreated (Wong-Riley and Carroll, 1984) macaques, but are also shown here for comparison with immunohistochemical staining patterns.

\section{Retina}

CO histochemistry (Fig. $2 A$ ) and immunohistochemistry (Fig. $2 B$ ) of the normal retina showed a strong correlation between $\mathrm{CO}$ activity and amount. Regions reactive by both methods included the photoreceptor inner segments, the cone pedicles, the outer and inner plexiform layers, some horizontal cells and ganglion cells, and unmyelinated portions of the optic nerve fibers. Preimmune control sections (Fig. 2C) showed only a lowlevel background, confirming the immunohistochemical specificity.

TTX treatment had mild but parallel effects on retinal $\mathrm{CO}$ activity (Fig. 2D) and protein (Fig. $2 E$ ) levels. Slight decreases 

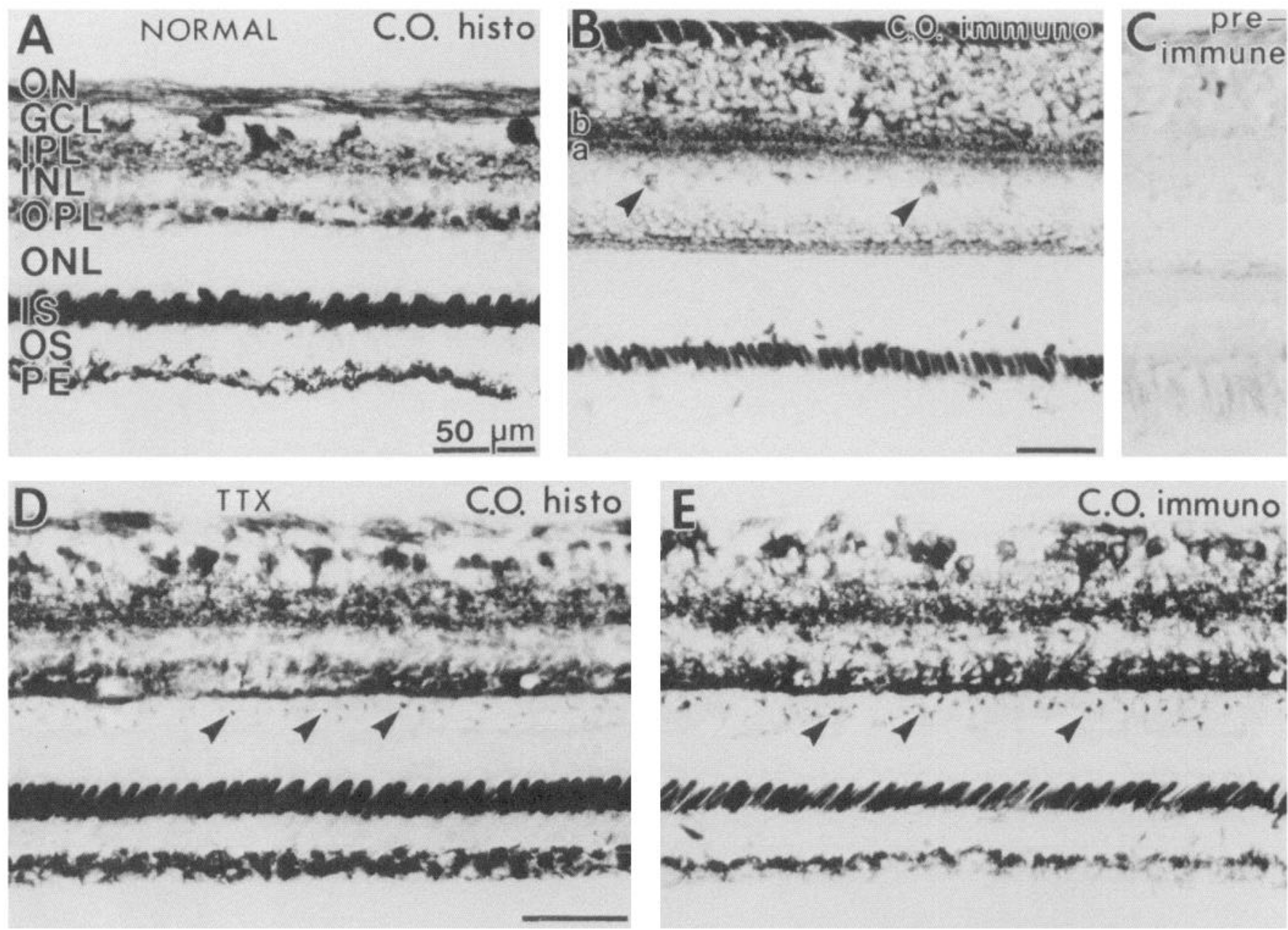

Figure 2. Cytochrome oxidase activity and amount in normal and experimental retina. $A-C$, Normal retina; $D$ and $E$, retina from TTX-treated eye. The sections were processed as indicated in each panel. The sections in $B$ and $C$ came from central retina; other sections came from peripheral retina. The pigmented epithelium is missing from the section in $B$. Note the similarity of the histochemical and immunohistochemical staining patterns in both the normal and experimental retinas. Note also the low level of nonspecific background seen in the preimmune stained section. In $B$, sublaminae $\mathrm{a}$ and $\mathrm{b}$ of the inner plexiform layer, which are separated by a lightly reactive zone, are marked; also marked (arrowheads) are darkly stained neurons in the inner nuclear layer, which are probably displaced ganglion cells (Kageyama and Wong-Riley, 1984). In $D$ and $E$, darkly reactive cone pedicles are visible (arrowheads). $O N$, Optic nerve fiber layer; GCL, ganglion cell layer; $I P L$, inner plexiform layer; $I N L$, inner nuclear layer; $O P L$, outer plexiform layer; $O N L$, outer nuclear layer; $I S$, photoreceptor inner segments; $O S$, photoreceptor outer segments; $P E$, pigmented epithelium.

in $\mathrm{CO}$ amount and activity were seen in optic nerve fibers, in some ganglion cells, and in the inner plexiform layer, but the overall patterns of $\mathrm{CO}$ staining remained essentially normal. Since action potentials in the retina are found only in ganglion cells and some amacrine cells (Werblin and Dowling, 1969), it is not surprising that treatment with TTX (which acts to block the ion channels mediating $\mathrm{Na}^{+}$action potentials) had little impact on $\mathrm{CO}$ in most retinal cells.

\section{Lateral geniculate nucleus}

The normal macaque LGN comprises 6 cellular laminae separated by zones of white matter (Fig. $3 A$ ). In the normal LGN, $\mathrm{CO}$ histochemistry (Fig. $3 \mathrm{C}$ ) and immunohistochemistry (Fig. $3 D$ ) showed similar patterns, with the cellular laminae being darkly reactive throughout the neuropil and in many cell bodies. Even small intralaminar variations in $\mathrm{CO}$ were similar histochemically and immunohistochemically; for example, in the adjacent sections shown in Figure 3, relatively dark reactivity was seen in the superior and medial portions of lamina 6 , and in lamina 3, by both histochemistry (Fig. $3 C$ ) and immunohistochemistry (Fig. $3 D$ ). Preimmune immunohistochemical controls showed only background staining (Fig. $3 B$ ).

TTX-treated animals showed marked reductions in $\mathrm{CO}$ activity (Fig. $3 E$ ) and amount (Fig. $3 F$ ) in LGN laminae innervated by the treated retina. The LGN shown in Figure 3, $E$ and $F$, was ipsilateral to the treated retina and had low CO levels in laminae 2, 3 , and 5 (which are driven by the ipsilateral retina; laminae 1,4 , and 6 are driven by the contralateral retina). The differences between laminae were more pronounced histochemically than immunohistochemically, due to the higher contrast of the histochemical method (Hevner and Wong-Riley, 1989a). Effects on $\mathrm{CO}$ were more striking in the ipsilateral than in the contralateral LGN; this difference was also noted previously by Wong-Riley and Carroll (1984) in their histochemical study. 

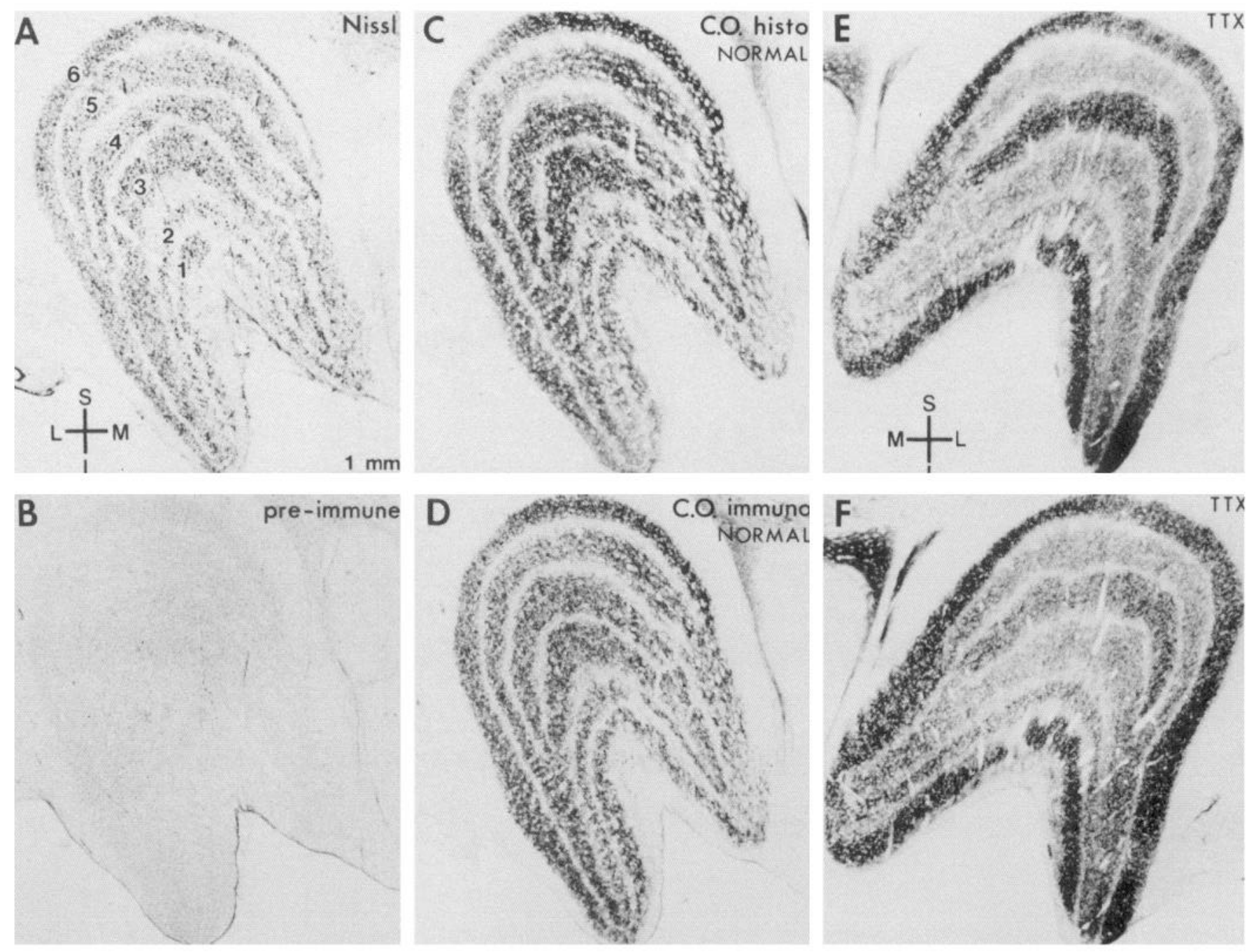

Figure 3. Cytochrome oxidase activity and amount in normal and experimental LGN. $A-\nu$, Normal LGN; $E$ and $F$, LGN from TTX-treated animal. The sections from the normal and the TTX-treated animals came from different anteroposterior positions in the nucleus. Sections were stained as follows: $A$, cresyl violet; $B$, preimmune serum; $C$ and $E$, CO histochemistry; $D$ and $F, C O$ immunohistochemistry. Adjacent sections are shown in $C$ and $D$, and in $E$ and $F$. In $A$, the cellular laminae are marked $1-6$. Note in $C$ and $D$ the parallel intralaminar variations in staining intensity seen histochemically and immunohistochemically; e.g., the superior-medial portion of lamina 6 is darkest stained by both methods. In $E$ and $F$, note that laminae 2,3 , and 5 are relatively pale; these laminae received their input from the TTX-treated eye. $I$, Inferior; $L$, lateral; $M$, medial; $S$, superior.

\section{Primary visual cortex}

The striate cortex was especially interesting for purposes of the present study because the $\mathrm{CO}$ histochemical pattern in this region has many distinctive features, most notably the supragranular "puffs" (Carroll and Wong-Riley, 1984), also known as "patches" (Horton and Hubel, 1981; Horton, 1984) or "blobs" (Livingstone and Hubel, 1988). The puffs are zones of high CO activity in cortical layers 2 and 3 that, despite their high levels of CO activity relative to interpuff regions, appear histologically identical to interpuff regions in a simple Nissl stain. We were interested to see if the concentration of $\mathrm{CO}$ protein differed between puffs and interpuffs, or if $\mathrm{CO}$ protein was, like the density of Nissl staining, equally concentrated in puffs and interpuffs (implying the presence of a more active form of $\mathrm{CO}$ in the puffs).

A Nissl stain of the normal cortex is shown in Figure $4 A$. Staining of adjacent normal sections by $\mathrm{CO}$ histochemistry (Fig.
$4 B$ ) and immunohistochemistry (Fig. $4 C$ ) revealed that the puffs were enriched in $\mathrm{CO}$ protein as well as activity. The correspondence between histochemically and immunohistochemically stained puffs was observed both in sections cut perpendicular (Fig. 4, $B, C$ ) and in sections cut tangential (Figs. 5, $A, B ; 6, A$, $B$ ) to the cortical surface. In addition to the puffs, other features of the histochemical and immunohistochemical patterns also generally matched as well. Layer $4 \mathrm{~A}$, which is noted for its broken, beaded pattern of $\mathrm{CO}$ histochemical staining in crosssection and its reticulated pattern of staining in tangential section, was stained immunohistochemically with those same patterns in both planes of section (Figs. 4, $B, C ; 6, A, B$ ). Preimmune controls showed no specific staining (Figs. $4 D, 5 C$ ). One difference between the two staining methods was that sometimes a few more cell bodies were labeled immunohistochemically than histochemically (cf. Fig. 4, B, C). This methodological difference was observed and discussed by us previously (Hevner and WongRiley, 1989a). Another apparent difference was that layers 1 and 

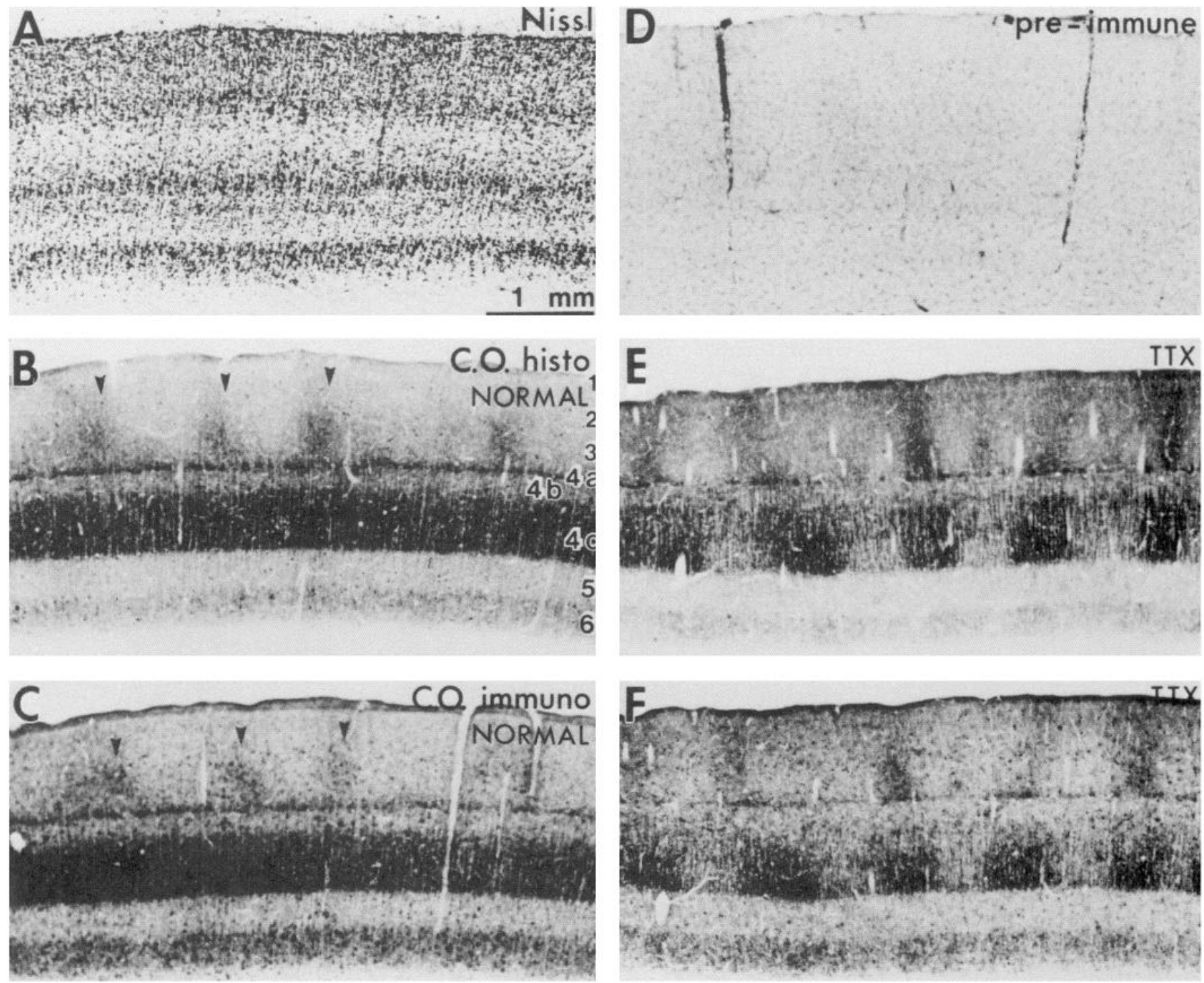

Figure 4. Cytochrome oxidase activity and amount in normal and experimental striate cortex: sections perpendicular to the cortical surface. A$D$, Normal cortex; $E$ and $F$, cortex from TTX-treated animal. Sections were stained as follows: $A$, cresyl violet; $B$ and $E$, CO histochemistry; $D$, preimmune serum; $C$ and $F, C O$ immunohistochemistry. Adjacent sections are shown in $A-D$, and in $E$ and $F$. Layers of the cortex are identified in $B$. Note the exact alignment between puffs stained histochemically and immunohistochemically in the normal cortex (arrowheads in $B$ and $C$ ); no corresponding variations in cell numerical density are visible in $A$. The dark and light ocular dominance columns in the experimental cortex are likewise precisely aligned.

6 of the cortex were sometimes more intensely stained immunohistochemically than histochemically (Fig. $4, B, C$ ), but such differences were not seen consistently (Figs. 5 and 6 ) and, in layer 1 , might have been due to edge effects.

In TTX-treated animals, decreased levels of $\mathrm{CO}$ protein (Figs. $4 F, 5 E, 6 D)$ were observed in the same columns or stripes of cortex in which $C O$ activity was reduced (Figs. $4 E, 5 D, 6 C$ ). The columns or stripes of low $\mathrm{CO}$ activity and protein concentration corresponded to classical ocular dominance columns normally driven by the treated eye (Wong-Riley and Carroll, 1984). The decreases in CO protein (and activity) were most prominent in layer $4 \mathrm{C}$, but were also visible in layers 2, 3, 4A, 5 , and 6. Throughout the cortical thickness, changes in $\mathrm{CO}$ activity were invariably accompanied by (and were thus at least partially due to) parallel changes in $\mathrm{CO}$ protein content; this was best shown in tangential sections through different cortical layers (Figs. 5 and 6).

\section{Densitometric analyses}

We further evaluated the histochemical and immunohistochemical results quantitatively by optical densitometry of cortical tangential sections (Table 1). To obtain estimates of the degree of CO activity and protein enrichment in puffs, puff and interpuff optical densities were read in histochemically and immunohistochemically stained tangential sections of normal cortex. Puffs stained histochemically were $32 \%$ darker than interpuffs, while puffs stained immunohistochemically were $19 \%$ darker than interpuffs. In both cases, staining differences between puffs and interpuffs were significant $(p<0.001)$.

To estimate the magnitude of the declines in $\mathrm{CO}$ activity and 

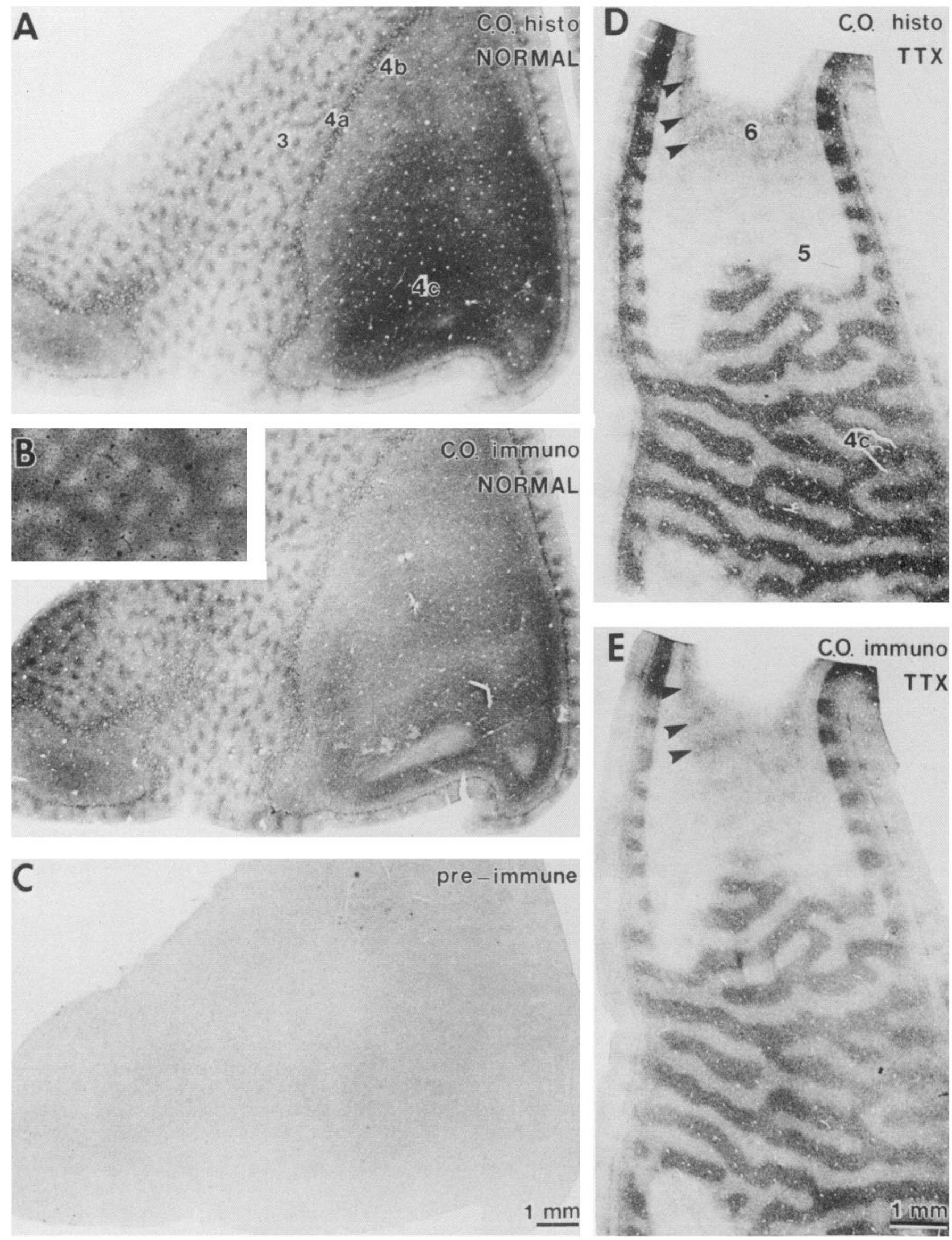
protein induced by TTX treatment, the optical densities of dark and light columns in cortical layer $4 \mathrm{C}$ were read in sections from TTX-treated animals. Light-column (low in CO) staining density was $20 \%$ decreased relative to dark-column (high in $\mathrm{CO}$ ) staining density in histochemically stained sections; in immunohistochemically stained sections, the decrease was $21 \%$. Differences between light- and dark-column staining densities were significant $(p<0.001)$ by both methods. Thus, the densitometric data yielded similar values for declines in $\mathrm{CO}$ activity and amount following TTX treatment, but somewhat different values for the degree of enrichment of $\mathrm{CO}$ activity and protein in the puffs. However, the relationships between optical density and $\mathrm{CO}$ amount or activity were not necessarily linear, nor did they necessarily follow parallel curves; convenient methods for evaluating these rclationships were not available.

\section{Discussion}

It has long been known that the activities of $\mathrm{CO}$ (Wong-Riley et al., 1978; Wong-Riley, 1989) and other energy metabolic enzymes (Dietrich et al., 1981, 1982) are regulated by neural functional activity. In the present study, we have shown that $\mathrm{CO}$ activity is regulated mainly at the level of amount rather than molecular activity (Fig. 1), at least over the time periods examined (3-4 weeks). Local differences in $\mathrm{CO}$ activity were uniformly found to reflect parallel differences in $\mathrm{CO}$ protein concentration in the present study, and in our previous study (Hevner and Wong-Riley, 1989a). [An alternative interpretation is that modulation of the molecular activity of the enzyme alters its immunoreactivity; for reasons discussed previously (Hevner and Wong-Riley, 1989a), this possibility seems unlikely.]

It is possible that the molecular activity of $\mathrm{CO}$ is regulated jointly with the amount of $\mathrm{CO}$, but we have found no evidence to favor this possibility, nor has evidence of molecular activity regulation come from biochemical studies. [It has, however, been hypothesized that the metabolic flux through $\mathrm{CO}$ may be regulated conformationally by ATP effects on the $K_{\mathrm{m}}$ for cytochrome $c$ (Huther and Kadenbach, 1986; Bisson et al., 1987; Gai et al., 1988).] Our densitometric results roughly indicated that $\mathrm{CO}$ activity and protein content were directly related, but we were not able to establish that optical density and CO activity or amount were necessarily linear in these experiments. Furthermore, the histochemical method generally shows more contrast in staining intensity (Hevner and Wong-Riley, 1989a) and lower background staining than the immunohistochemical method.

Cytochrome oxidase is not unique in being amount-regulated by nerve cell activity; levels of other molecules important to brain function are also activity-dependent. The list of such molecules includes GABA (Hendry and Jones, 1988), tachykinin (Hendry et al., 1988), and calmodulin-dependent protein kinase (Hendry and Kennedy, 1986). These other molecules have no direct role in oxidative energy metabolism, but instead are involved in more specialized functions of the nervous system such as synaptic transmission. Hendry and Jones (1988) also showed

\begin{tabular}{|c|c|c|}
\hline \multirow{2}{*}{$\begin{array}{l}\text { Cortical layer, } \\
\text { treatment, } \\
\text { and region }\end{array}$} & \multicolumn{2}{|c|}{ Relative optical density (mean \pm SD) } \\
\hline & Histochemistry & $\begin{array}{l}\text { Immunohisto- } \\
\text { chemistry }\end{array}$ \\
\hline \multicolumn{3}{|c|}{ Normal layer 2 and 3} \\
\hline Interpuff & $1.00 \pm 0.05$ & $1.00 \pm 0.04$ \\
\hline Puff & $1.32 \pm 0.04$ & $1.19 \pm 0.04$ \\
\hline \multicolumn{3}{|c|}{ TTX-treated (4 week) layer $4 \mathrm{C}$} \\
\hline Dark column & $1.00 \pm 0.04$ & $1.00 \pm 0.08$ \\
\hline Light column & $0.80 \pm 0.02$ & $0.79 \pm 0.08$ \\
\hline
\end{tabular}

All sections were cut tangential to the cortical surface. Adjacent histochemically and inmunohistochemically stained sections (normal and experimental) were used for densitometry. Densitometric readings were normalized to yield interpuff(normal cortex) or dark column (experimental cortex) densities of 1.00. For each region, 25 readings were taken. All puff/interpuff and dark-column/light-column differences within a section were significant ( $p<0.001$, Student's $t$ test, 2-tailed). Optical density may not be linearly proportional to $\mathrm{CO}$ activity or amount.

that cell death does not follow TTX treatment in protocols such as the one used in the present study, and thus cannot account for altered levels of molecules. While it is important to know that levels of various molecules are affected by nerve cell activity, we attach more significance in the present study to the implications for oxidative metabolic regulation than to the observation that levels of yet another molecule are activity-dependent.

While the activities of oxidative pathway enzymes other than $\mathrm{CO}$ are known to be regulated by neural functional activity (Dietrich et al., 1981, 1982), the biochemical basis (amount regulation or molecular activity regulation) for the activity changes was not determined in previous studies. It is reasonable to suppose that other energy-metabolic enzymes, especially other mitochondrial enzymes, are also amount-regulated. This hypothesis is supported by studies done in our laboratory, which have shown that the fraction of tissue volume occupied by mitochondria decreases in visual cortical puffs specific to injectedeye columns following monocular TTX treatment (Wong-Riley et al., 1989a, b). Similar correlations between changes in oxidative enzyme activities and mitochondrial volume fraction have been observed in skeletal muscle following contractile stimulation (Schwerzmann et al., 1989).

The finding that CO activity is regulated at the level of amount further implies that the rates of $\mathrm{CO}$ synthesis and/or degradation are regulated. Further investigation of the mechanisms of synthetic or degradative rate regulation will be difficult, since in general the processes of mitochondrial biogenesis and breakdown (and their regulation) are as yet poorly understood (Luzikov, 1985). The most rapid progress is likely to come in investigating regulation of $\mathrm{CO}$ gene expression, since genomic and cDNA clones encoding most of the 13 subunits of mammalian $\mathrm{CO}$ (of which 3 are encoded in the mitochondrial genome and

\footnotetext{
Figure 5. Cytochrome oxidase activity and amount in normal and experimental striate cortex: sections tangential to the cortical surface. $A-C$, Normal cortex; $D$ and $E$, cortex from TTX-trcated animal. Sections werc stained as indicated in each panel. The sections shown in $A-C$, and in $D$ and $E$, were adjacent. Layers of the cortex are indicated by numbers in $A$ and $D$. The inset in $B$ shows a section of cortical layers 2 and 3 stained by indirect immunofluorescence. In the normal cortex, the puffs of layers 2 and 3 (visible as dark spots, or as light spots in the immunofluorescence micrograph), and the reticulated pattern of layer $4 \mathrm{~A}$, form closely matched patterns histochemically and immunohistochemically. In the experimental cortex, ocular dominance stripes are visible in layers $4 C$ and 6 (arrowheads in $D$ and $E$ ) by both histochemistry and immunohistochemistry.
} 

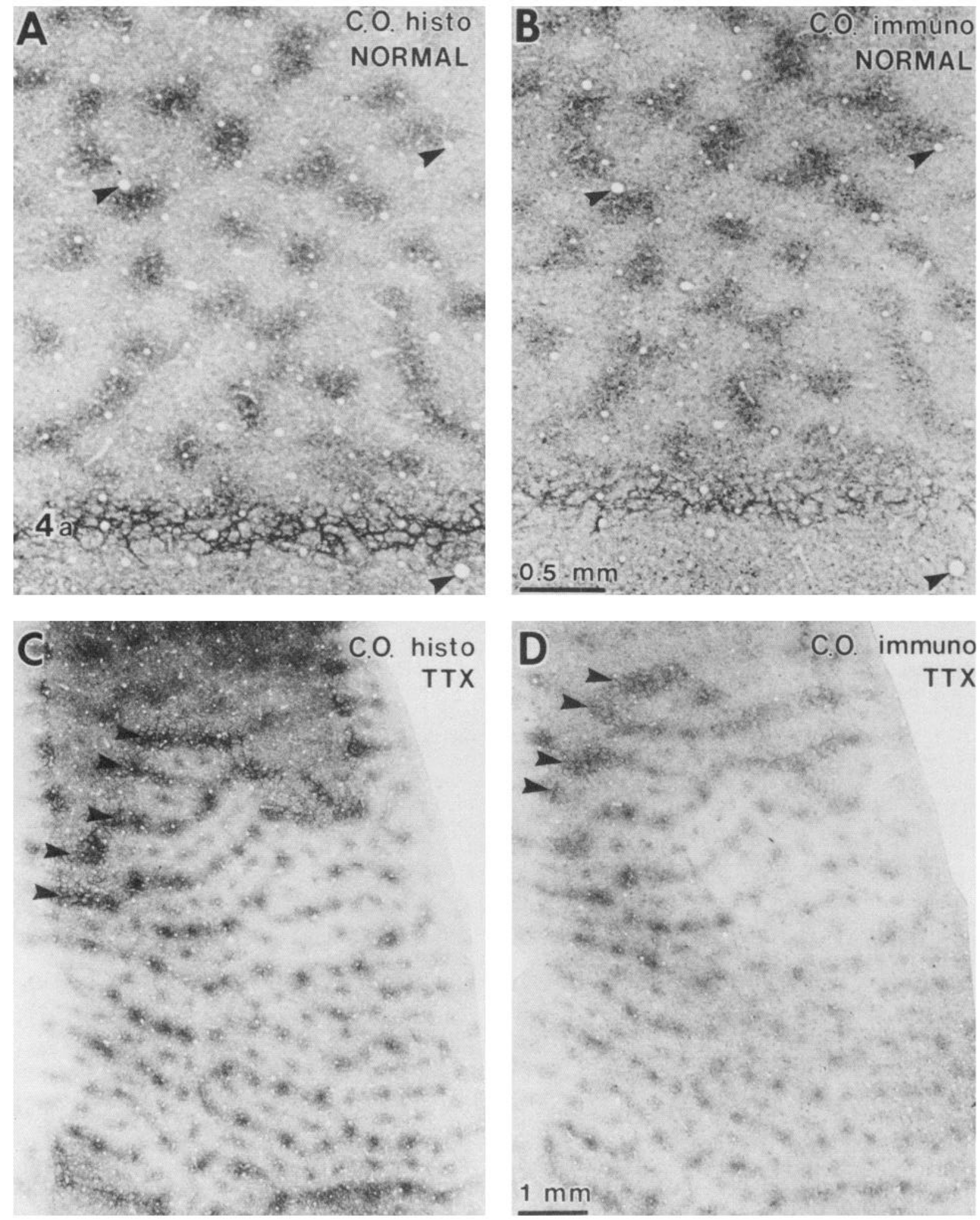

Figure 6. Cytochrome oxidase activity and amount in normal and experimental striate cortex: layers $2-4 \mathrm{a}$. $A$ and $B$, Normal cortex; $C$ and $D$, cortex from TTX-treated animal. Sections were stained as indicated in each panel. Adjacent sections are shown in $A$ and $B$, and in $C$ and $D$. In the normal cortex, immunohistochemically stained puffs lie in exact register with histochemically stained puffs, as shown by reference to major blood vessels (arrowheads in $A$ and $B$ ). Layer 4a (labeled in $A$ ) is displaced between panels $A$ and $B$ because it is no thicker than the sections ( 30 $\mu \mathrm{m})$. In the experimental cortex, note the alternating rows of small, pale puffs and large, dark puffs, visible both histochemically and immunohistochemically. Layer 4a (arrowheads in $C$ and $D$ ) is broken into ocular dominance columns in the cortex from the TTX-treated animal. 
10 in the nuclear genome, making $\mathrm{CO}$ a "bigenomic" enzyme) have recently been isolated and sequenced (Anderson et al., 1981, 1982; Bibb et al., 1981; Lomax et al., 1984; Parimoo et al., 1984; Bachman et al., 1987; Suske et al., 1987; Zeviani et al., 1987, 1988; Rizzuto et al., 1988, 1989; Schlerf et al., 1988; Goto et al., 1989; Taanman et al., 1989). Studies of CO gene expression in skeletal muscle have generally shown that $\mathrm{CO}$ mRNA levels, and mitochondrial DNA levels, are regulated by cellular functional activity (Williams, 1986; Williams et al., 1986, 1987; Hood et al., 1989).

The technique of in situ hybridization should prove useful in future studies of $\mathrm{CO}$ gene expression in the nervous system, where the spatial distribution of molecules is as important as their overall levels. Of major interest will be the question of how mitochondrial and nuclear gene expression are coordinated in time and space (especially since mitochondrial genes may be scattered throughout the neuron, while nuclear genes are found only in the soma). Studies of skeletal muscle have produced conflicting results on the question of nuclear-mitochondrial coordination, indicating that levels of nuclear and mitochondrial mRNAs are (Hood et al., 1989) or are not (Williams et al., 1987) coordinately regulated.

The finding that $\mathrm{CO}$ activity is regulated at the level of amount suggests that the response time of the system may be rather slow, on the order of the half-life for enzyme degradation (Schimke and Doyle, 1970), which is approximately 7-10 d in vivo, at least in the rat liver (Ip et al., 1974). The time course for $\mathrm{CO}$ activity change is indeed rather slow in most experiments; changes in $\mathrm{CO}$ activity are usually observed over periods of days to weeks (reviewed by Wong-Riley, 1989). Experimentally induced changes in $\mathrm{CO}$ activity have, however, been observed after only $8 \mathrm{hr}$ (Mawe and Gershon, 1986). In future studies, it will be important to determine if immunohistochemical changes occur as rapidly as histochemical changes, especially soon after TTX treatment or other functional manipulation. Such studies will indicate if changes in $\mathrm{CO}$ activity can always be attributed to changes in $\mathrm{CO}$ amount, or if regulation of the turnover number occurs during early stages of functional adjustment and is followed by regulation of the amount of the enzyme.

\section{References}

Anderson, S., A. T. Bankier, B. G. Barrell, M. H. L. de Bruijn, A. R. Coulson, J. Drouin, I. C. Eperon, D. P. Nierlich, B. A. Roe, F. Sanger, P. H. Schreier, A. J. H. Smith, R. Staden, and I. G. Young (1981) Sequence and organization of the human mitochondrial genome. Nature 290: $457-465$.

Anderson, S., M. H. L. de Bruijn, A. R. Coulson, I. C. Eperon, F. Sanger, and I. G. Young (1982) Complete sequence of bovine mitochondrial DNA. Conserved features of the mammalian mitochondrial genome. J. Mol. Biol. 156: 683-717.

Bachman, N. J., M. I. Lomax, and L. I. Grossman (1987) Two bovine genes for cytochrome $c$ oxidase subunit IV: A processed pseudogene and an expressed gene. Gene 55: 219-229.

Bibb, M. J., R. A. Van Etten, C. T. Wright, M. W. Walber, and D. A. Clayton (1981) Sequence and genc organization of mouse mitochondrial DNA. Cell 26: 167-180.

Bisson, R., G. Schiavo, and C. Montecucco (1987) ATP induces conformational changes in mitochondrial cytochrome $c$ oxidase. Effect on the cytochrome $c$ binding site. J. Biol. Chem. 262: 5992-5998.

Carroll, E. W., and M. T. T. Wong-Riley (1984) Quantitative light and electron microscopic analysis of cytochrome oxidase-rich zones in the striate cortex of the squirrel monkey. J. Comp. Neurol. 222: $1-17$.

Dietrich, W. D., D. Durham, O. H. Lowry, and T. A. Woolsey (1981)
Quantitative histochemical effects of whisker damage on single identified cortical barrels in the adult mouse. J. Neurosci. 1: 929-935.

Dietrich, W. D., D. Durham, O. H. Lowry, and T. A. Woolsey (1982) "Increased" sensory stimulation leads to changes in energy-related enzymes in the brain. J. Neurosci. 2: 1608-1613.

Erecinska, M., and I. A. Silver (1989) ATP and brain function. J. Cerebr. Blood Flow Metab. 9: 2-19.

Gai, W.-Z., S.-M. Sun, Y.-Z. Ding, J. A. Freedman, and S. H. P. Chan (1988) Two monoclonal antibody lines directed against subunit IV of cytochrome oxidase: A study of opposite effects. Arch. Biochem. Biophys. 266: 628-638.

Goto, Y., N. Amuro, and T. Okazaki (1989) Nucleotide sequence of cDNA for rat brain and liver cytochrome $c$ oxidase subunit IV. Nucl. Acids Res. 17: 2851.

Hendry, S. H. C., and E. G. Jones (1988) Activity-dependent regulation of GABA expression in the visual cortex of adult monkeys. Neuron 1: 701-712.

Hendry, S. H. C., and M. B. Kennedy (1986) Immunoreactivity for a calmodulin-dependent protein kinase is selectively increased in macaque striate cortex after monocular deprivation. Proc. Natl. Acad. Sci. USA 83: 1536-1540.

Hendry, S. H. C., E. G. Jones, and N. Burstein (1988) Activity-dependent regulation of tachykinin-like immunoreactivity in neurons of monkey visual cortex. J. Neurosci. 8: 1225-1238.

Hevner, R. F., and M. Wong-Riley (1988) Cytochrome oxidase immunohistochemistry in the primate visual cortex. Soc. Neurosci. Abstr. 14: 601 .

Hevner, R. F., and M. T. T. Wong-Riley (1989a) Brain cytochrome oxidase: Purification, antibody production, and immunohistochemical/histochemical correlations in the CNS. J. Neurosci. 9: 3884 3898.

Hevner, R. F., and M. T. T. Wong-Riley (1989b) Regulation of cytochrome oxidase protein levels by functional activity in the macaque monkey visual system. Soc. Neurosci. Abstr. 15: 1107.

Hood, D. A., R. Zak, and D. Pette (1989) Chronic stimulation of rat skeletal muscle induces coordinate increases in mitochondrial and nuclear mRNAs of cytochrome-c-oxidase subunits. Eur. J. Biochem. 179: $275-280$.

Horton, J. C. (1984) Cytochrome oxidase patches: A new cytoarchitectonic feature of monkey visual cortex. Phil. Trans. R. Soc. Lond. B 304: 199-253.

Horton, J. C., and D. H. Hubel (1981) Regular patchy distribution of cytochrome oxidase staining in primary visual cortex of macaque monkey. Nature 292: 762-764.

Huther, F.-J., and B. Kadenbach (1986) Specific effects of ATP on the kinetics of reconstituted bovine heart cytochrome- $c$ oxidase. FEBS Lett. 207: 89-94.

Ip, M. M., P. Y. Chee, and R. W. Swick (1974) Turnover of hepatic mitochondrial ornithine aminotransferase and cytochrome oxidase using $\left[{ }^{14} \mathrm{C}\right]$ carbonate as tracer. Biochim. Biophys. Acta 354: 29-38.

Kadenbach, B., L. Kuhn-Nentwig, and U. Buge (1987) Evolution of a regulatory enzyme: Cytochrome-c oxidase (complex IV). Curr. Topics Bioenerg. 15: 113-161.

Kageyama, G. H., and M. T. T. Wong-Riley (1984) The histochemical localization of cytochrome oxidase in the retina and lateral geniculate nucleus of the ferret, cat, and monkey, with particular reference to retinal mosaics and on/off-center visual channels. J. Neurosci. 4: 24452459 .

Livingstone, M., and D. Hubel (1988) Segregation of form, color, movement, and depth: Anatomy, physiology, and perception. Science 240: 740-749.

Lomax, M. I., N. J. Bachman, M. S. Nasoff, M. H. Caruthers, and L. I. Grossman (1984) Isolation and characterization of a cDNA clone for bovine cytochrome $c$ oxidase subunit IV. Proc. Natl. Acad. Sci. USA 81: 6295-6299.

Luo, X. G., R. F. Hevner, and M. T. T. Wong-Riley (1989) Double labeling of cytochrome oxidase and $\gamma$-aminobutyric acid in central nervous system neurons of adult cats. J. Neurosci. Meth. 30: 189195.

Luzikov, V. N. (1985) Mitochondrial Biogenesis and Breakdown, Plenum, New York.

Mawe, G. M., and M. D. Gershon (1986) Functional heterogeneity in the myenteric plexus: Demonstration using cytochrome oxidase as a verified cytochemical probe of the activity of individual enteric neurons. J. Comp. Neurol. 249: 381-391. 
Morgan-Hughes, J. A. (1986) Mitochondrial diseases. Trends Neurosci. 9: 15-19.

Parimoo, S., R. S. Seelan, S. Desai, G. Buse, and G. Padmanaban (1984) Construction of a cDNA clone for a nuclear-coded subunit of cytochrome $c$ oxidase from rat liver. Biochem. Biophys. Res. Commun. 118: 902-909.

Riccio, R. V., and M. A. Matthews (1985) The effect of intraocular injection of tetrodotoxin on fast axonal transport of $\left[{ }^{3} \mathrm{H}\right]$ proline- and $\left[{ }^{3} \mathrm{H}\right]$ fucose-labeled materials in the developing rat optic nerve. Neuroscience 16: 1027-1039.

Rizzuto, R., H. Nakase, M. Zeviani, S. DiMauro, and E. A. Schon (1988) Subunit Va of human and bovine cytochrome $c$ oxidase is highly conserved. Gene 69: 245-256.

Rizzuto, R., H. Nakase, B. Darras, U. Francke, G. M. Fabrizi, T. Mengel, F. Walsh, B. Kadenbach, S. DiMauro, and E. A. Schon (1989) A gene-specifying subunit VIII of human cytochrome $c$ oxidase is localized to chromosome 11 and is expressed in both muscle and non-muscle tissues. J. Biol. Chem. 264: 10595-10600.

Schimke, R. T., and D. Doyle (1970) Control of enzyme levels in animal tissues. Annu. Rev. Biochem. 39: 929-976.

Schlerf, A., M. Droste, M. Winter, and B. Kadenbach (1988) Characterization of two different genes (cDNA) for cytochrome $c$ oxidase subunit VIa from heart and liver of the rat. EMBO J. 7: 2387-2391.

Schwerzmann, K., H. Hoppeler, S. R. Kayar, and E. R. Weibel (1989) Oxidative capacity of muscle and mitochondria: Correlation of physiological, biochemical, and morphometric characteristics. Proc. Natl. Acad. Sci. USA 86: 1583-1587.

Suske, G., T. Mengel, M. Cordingley, and B. Kadenbach (1987) Molecular cloning and further characterization of cDNAs for rat nuclearencoded cytochrome $c$ oxidase subunits VIc and VIII. Eur. J. Biochem. 168: 233-237.

Taanman, J.-W., C. Schrage, N. Ponne, P. Bolhuis, H. de Vries, and E. Agsteribbe (1989) Nucleotide sequence of cDNA encoding subunit VIb of human cytochrome $c$ oxidase. Nucl. Acids Res. 17: 1766.

Werblin, F. S., and J. E. Dowling (1969) Organization of the retina of the mudpuppy, Necturus maculosus. II. Intracellular recording. J. Neurophysiol. 32: 339-355.

Williams, R. S. (1986) Mitochondrial gene expression in mammalian striated muscle. Evidence that variation in gene dosage is the major regulatory event. J. Biol. Chem. 261: 12390-12394.
Williams, R. S., S. Salmons, E. A. Newsholme, R. E. Kaufman, and J. Mellor (1986) Regulation of nuclear and mitochondrial gene expression by contractile activity in skeletal muscle. J. Biol. Chem. 261: 376-380.

Williams, R. S., M. Garcia-Moll, J. Mellor, S. Salmons, and W. Harlan (1987) Adaptation of skeletal muscle to increased contractile activity. Expression of nuclear gencs encoding mitochondrial protcins. J. Biol. Chem. 262: 2764-2767.

Wong-Riley, M. (1979) Changes in the visual system of monocularly sutured or enucleated cats demonstrable with cytochrome oxidase histochemistry. Brain Res. 171: 11-28.

Wong-Riley, M. T. T. (1989) Cytochrome oxidase: An endogenous metabolic marker for neuronal activity. Trends Neurosci. 12:94-101.

Wong-Riley, M., and E. W. Carroll (1984) Effect of impulse blockage on cytochrome oxidase activity in monkey visual system. Nature 307 : 262-264.

Wong-Riley, M., and D. A. Riley (1983) The effect of impulse blockage on cytochrome oxidase activity in the cat visual system. Brain Res. 261: 185-193.

Wong-Riley, M. T. T., M. M. Merzenich, and P. A. Leake (1978) Changes in endogenous enzymatic reactivity to $\mathrm{DAB}$ induced by neuronal inactivity. Brain Res. 141: 185-192.

Wong-Riley, M. T. T., S. C. Tripathi, T. C. Trusk, and D. A. Hoppe (1989a) Effect of retinal impulse blockage on cytochrome oxidaserich zones in the macaque striate cortex: I. Quantitative electronmicroscopic (EM) analysis of neurons. Visual Neurosci. 2: 483-497.

Wong-Riley, M. T. T., T. C. Trusk, S. C. Tripathi, and D. A. Hoppe (1989b) Effect of retinal impulse blockage on cytochrome oxidaserich zones in the macaque striate cortex: II. Quantitative electronmicroscopic (EM) analysis of neuropil. Visual Neurosci. 2: 499-514.

Zeviani, M., M. Nakagawa, J. Herbert, M. I. Lomax, L. I. Grossman, A. A. Sherbany, A. F. Miranda, S. DiMauro, and E. A. Schon (1987) Isolation of a cDNA clone encoding subunit IV of human cytochrome $c$ oxidase. Gene 55: 205-217.

Zeviani, M., S. Sakoda, A. A. Sherbany, H. Nakase, R. Rizzuto, C. E. Samitt, S. DiMauro, and E. A. Schon (1988) Sequence of cDNAs encoding subunit $\mathrm{Vb}$ of human and bovine cytochrome $c$ oxidase. Gene 65: 1-11. 